DClarivate

JSER

Web of Science"

Egyptian Knowledge Bank بنك المعرفة المصري
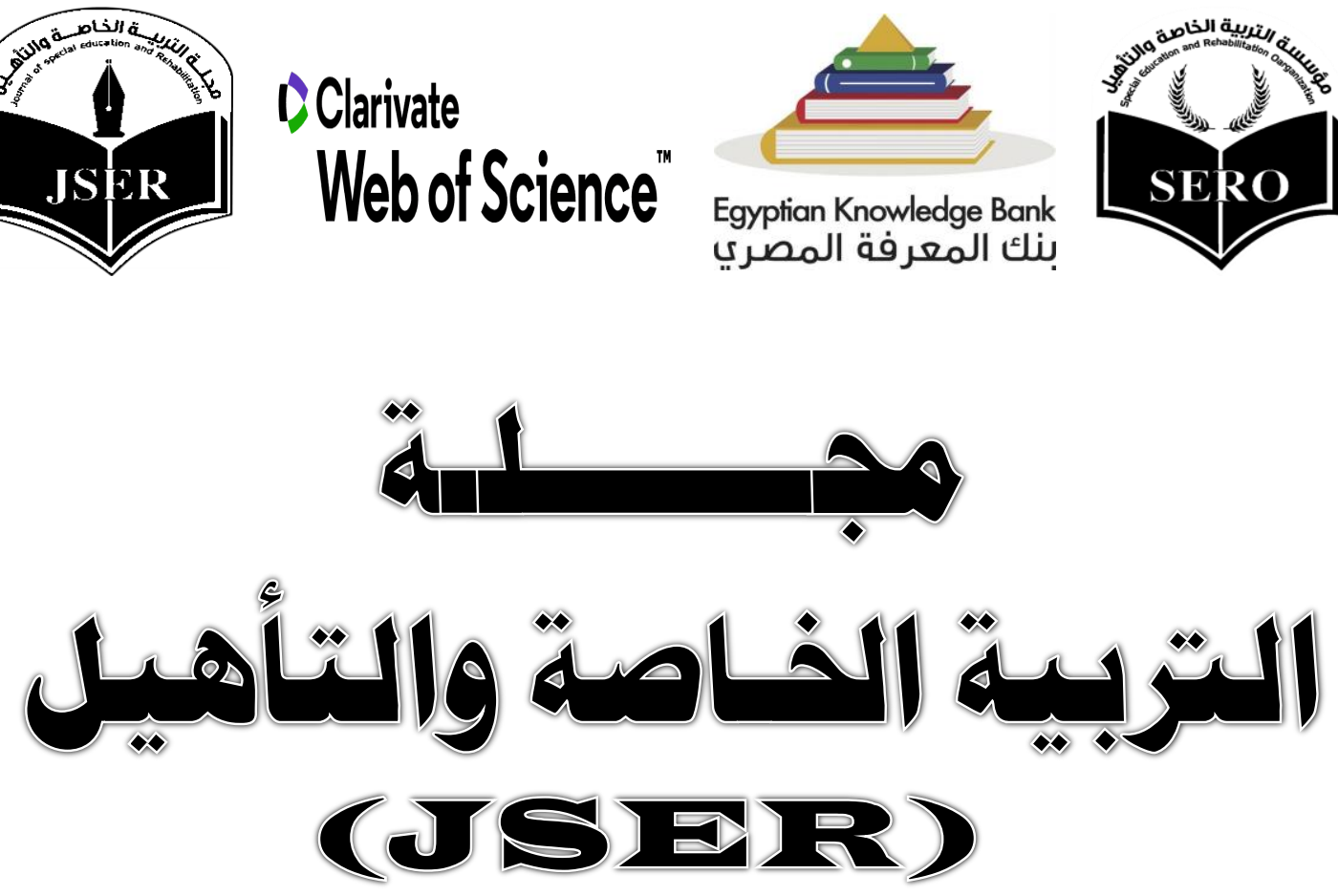

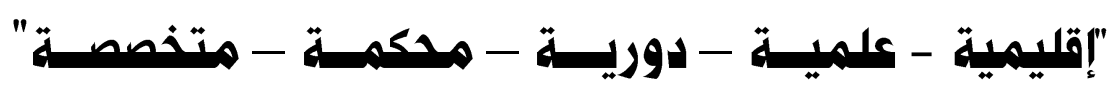

\title{
تصسطدر عـن
}

مؤسسة التربية الخاصة والتأهيل (SERO)

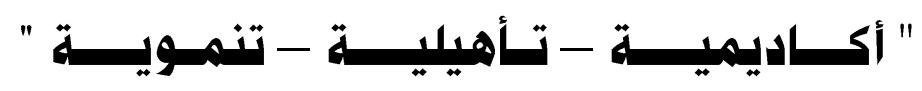

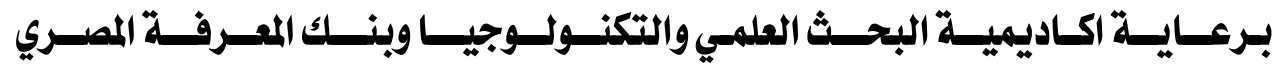

"أول مجلة متذصصة في مجال التربية الخاصة في الوطن العربي - صدر العدد الأول أكتوبر با.؟"

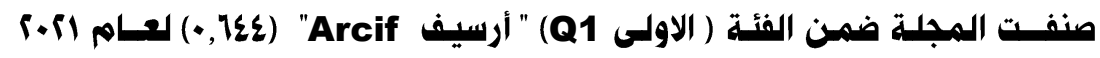

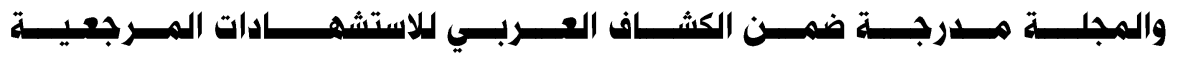

التي يتم استضافتها عبر منصة Clarivate Web of Science لادراج المجلة في قاعده بيانات ISI

ترقيم دولي : 0806 - 08

الترقيم الإلكتروني: 2735-3141

رقهم إيــداع: •

المجلد الثاني عشر - العدد r؟ - الجزيء الثاني - (مايو ، (I+؟) 


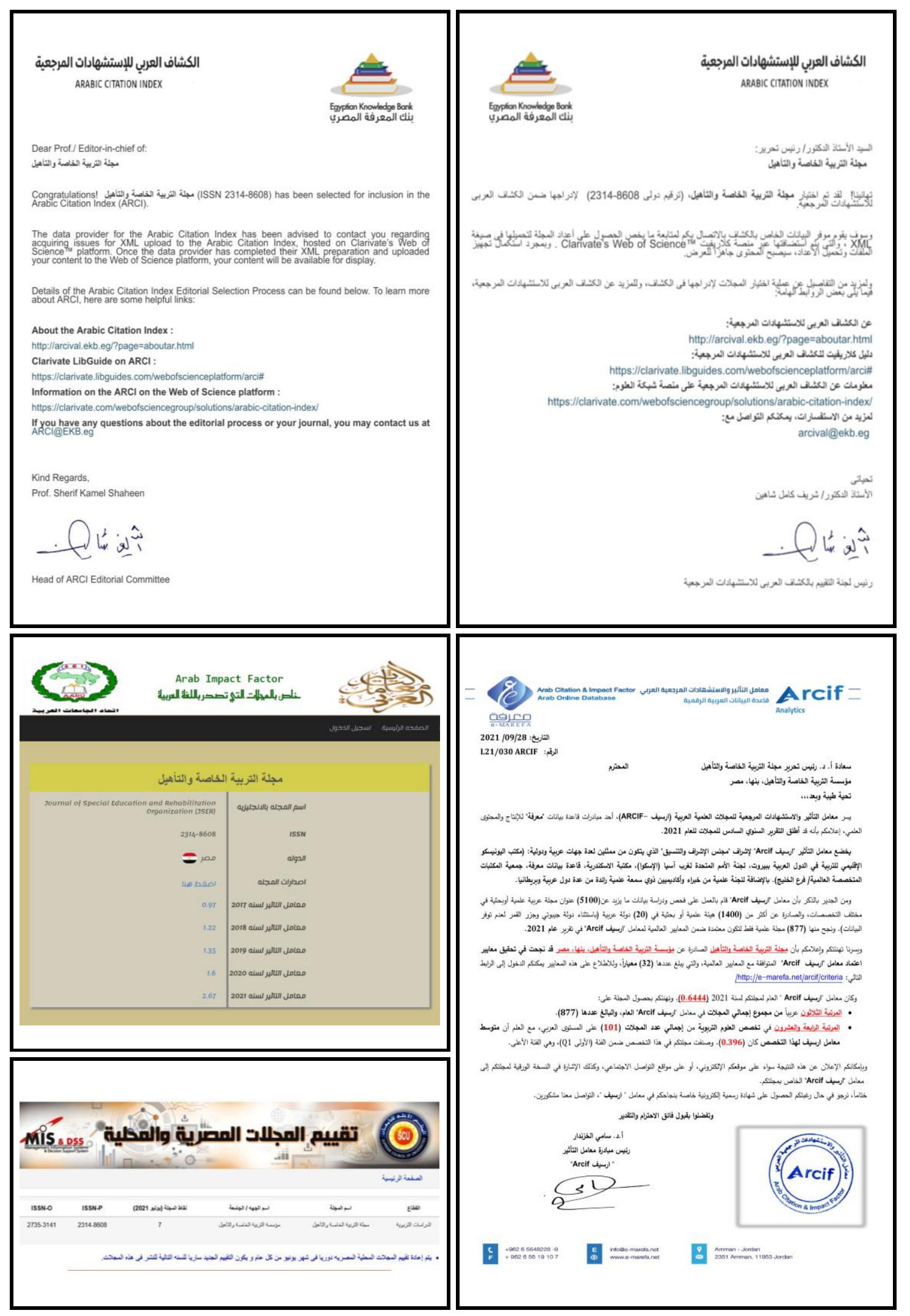




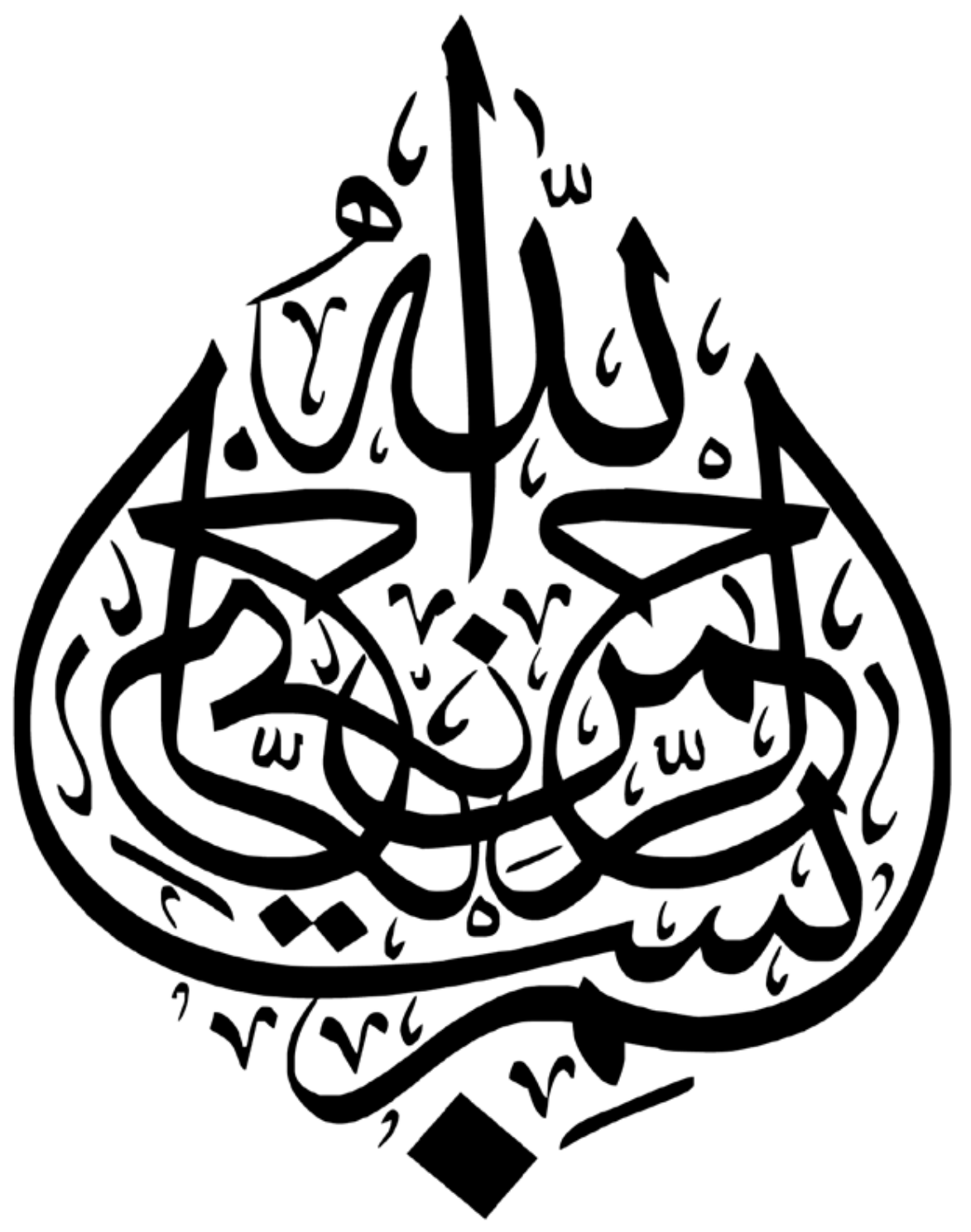




\section{(*)}

أ.د/ عبد العـزيز السـرطساوي

جــــــة الأمســارات-الإمارات

أ.د / عبد العرليز بن هممد العبد الجبار جامعة الملك سعود- السعودية

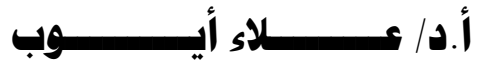

جامعة الخليج العربي- البحرين

أ.د الد هاتياس جرونكا Matthias Grïnke

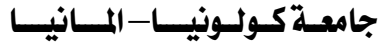

University of Cologne-German

$$
\begin{aligned}
& \text { أ.د / نساصر بن علي الموسى }
\end{aligned}
$$

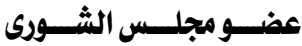

أمين عام التربية الخاصة بالسعودية سابقا

$$
\text { أ.د / نساصر بن سعد العجمي لئي }
$$

المدير التنفيذي لبرنامج الوصول الشامل بجامعة الملك سعود

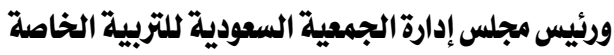

أ.د / نماتي أحمد بني يونس

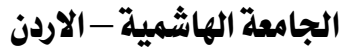

$$
\text { أ.د / عبدالكـريسم الهسـين }
$$

رئيس قسم التربية الخاصة - جامعة الملك سعود

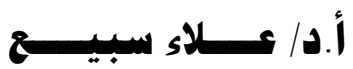

المستشار الاقليمي لشؤون الاعاقة (الاسكوا)-بيروت

\section{أ.د / هارفى رود}

جامعة شمال كولورادو - الولايات المتحلدة الامريكية

University of Northern Colorado-USA
أ. د/ أحمد عبد|لعزيلز التميهمي

جامعة الملك سعود- السعودية

أ. د/ أحمد ههدى هصطفي

أستاذ علد النفس - مقرر اللجنة العلمية لترقية الأساتذة

والأساتذة المساعدين بجمهورية مصر العربية (جامعة الأزهر )

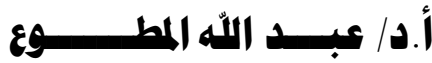

$$
\begin{aligned}
& \text { جامعة شقراء - السعودية }
\end{aligned}
$$

أ.د/ آهال عبدالسميميع باظة

أستاذ الصحة النفسية والتربية الخاصة وعميدكلية التربية كفر الشيخسابقا - مقرر اللجنة العلمية لترقية الأساتذة والأساتذة التهاية

المساعدين بجمهورية مصر العربية

أ. د/ جميـل همهـود الصمادي

الجـامعـة الأردنيــة - الأردن

أ.د/ همد بلية همد العجمي الهمي

الهيئة العامة للتعليم التطبيقي والتدريب - الكويت

أ.د أد ريتشارد هانزير Richard Mainzer

مستشار مجلس الأطفال غير العاديين الامريكى (CEC)

أ.د/ ريسد تـرنبـل Rud Turnbull

جامعة كانسس - أمريكا

أ.د / سميمــان البرشيسدي

جامعة الملك فيصل - السعودية

أ.د / طـارق بن صـالـح الريسل

جامعة الملك سعود - السعودية

$$
\text { أ.د هـ هـريسيم الشــيراوى }
$$

جامعة الخليج العربي - البحرين 


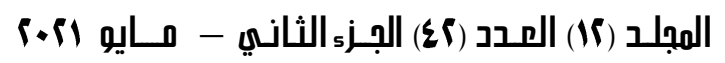

مجلة التربيـة الفـامة والتاهـيل

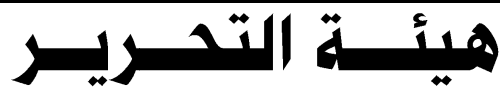

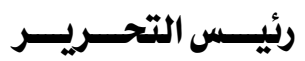

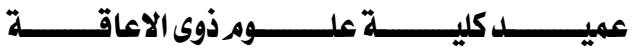

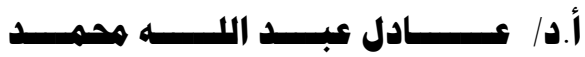

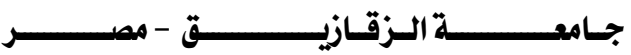

$$
\text { مسـليـــر التحريـر }
$$

جامعــــــة الملـــــــك ســـــــود - الســــــودية)

أ.د/ إبـراهـيم بـن سعــد أبــو نـيـان

$$
\text { أعضـاء هيئـــة التحريـر }
$$
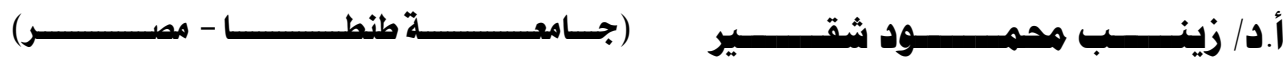

( جامعــه عبدالحميـــــــن بـــاديس - الجزائـــر )

أ.د / هنصـــــوريه عبــــدالقادر دويلـــي

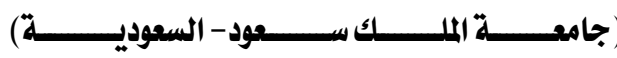

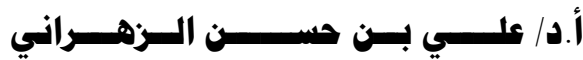

( الهيئة العامة للتعليم التطبيقي والتدريب - الكويت)

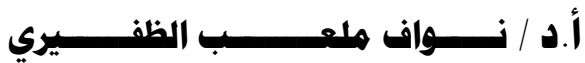

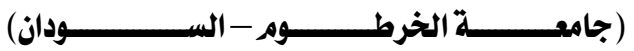

أ.د / همهـــــ كمــال أبــو الفتــــوح

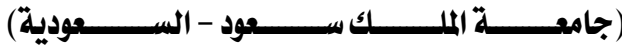

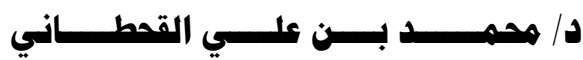

عودية)

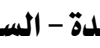
$ج$ (جامع ()
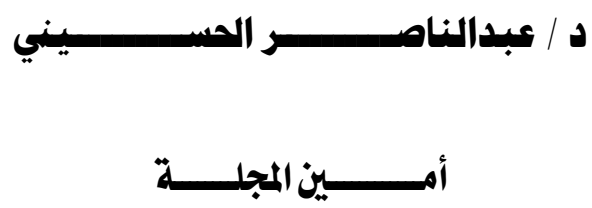

( مؤسســـة التربيـــة الخاصـــة والتأهيـلـل التربـــوي )

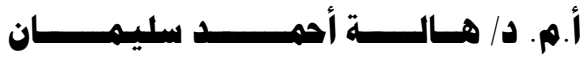

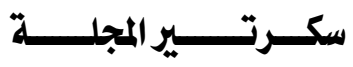

( مؤسسـة التزبيـة الخاصـة والتأهيل التزبـوي - مصرر )

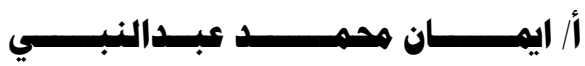




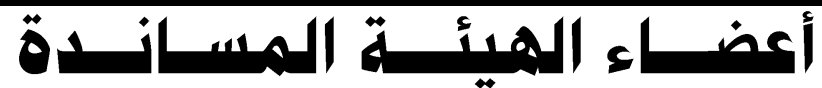

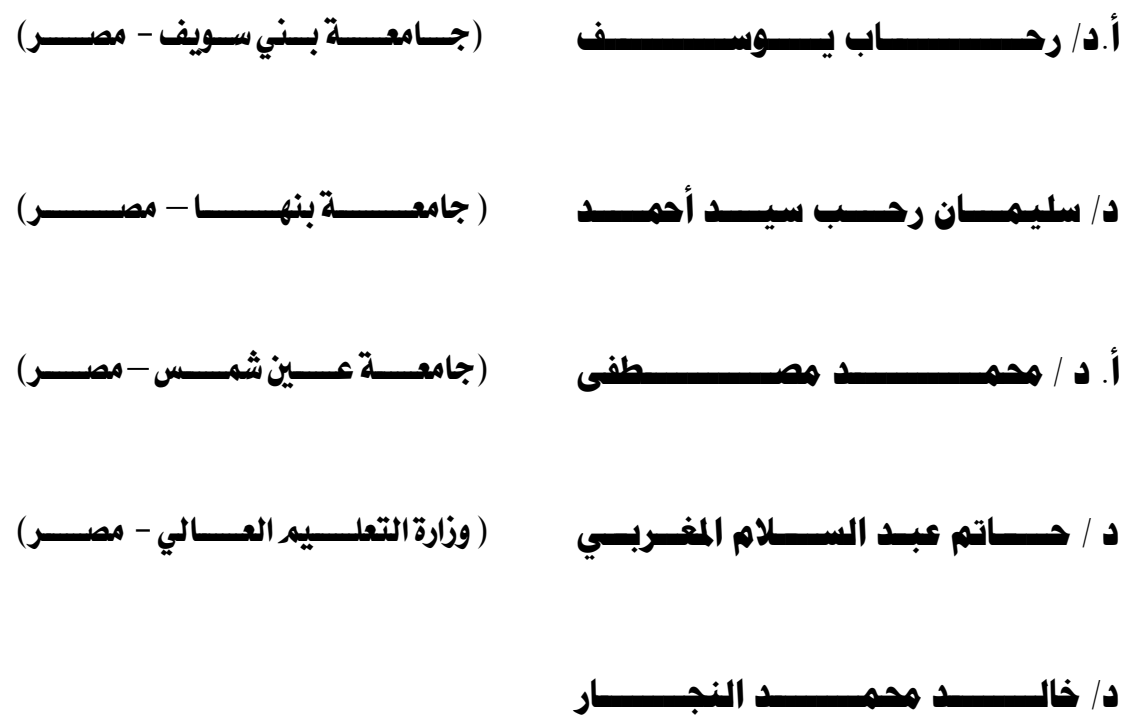




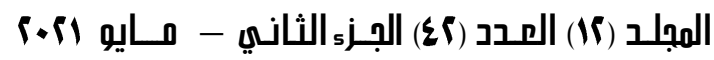

مجلة التربيـة الفـامة والتاههيل

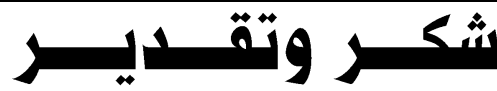

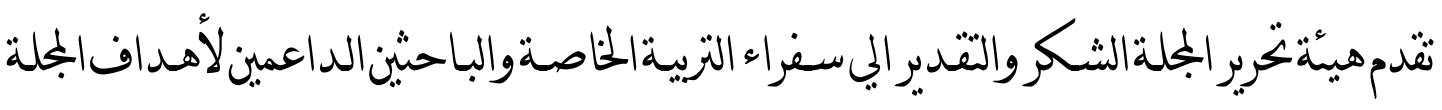

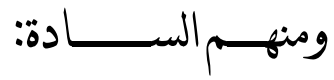

( كلية الدراسات العليا للتربية - جامعة القاهرة - مصر )

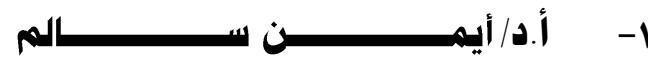

(

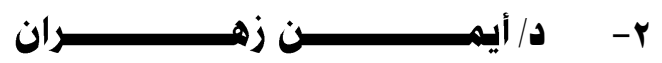

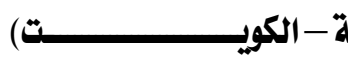

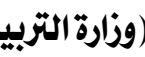

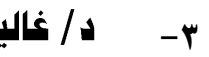

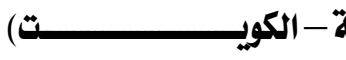

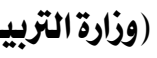

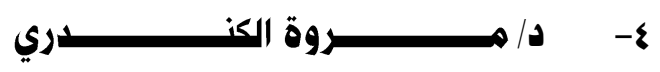

عوديةة)

ن

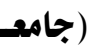

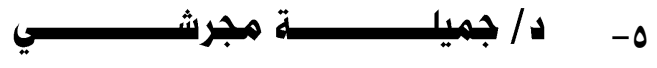

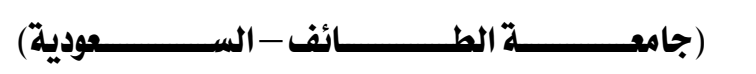

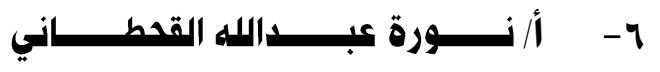




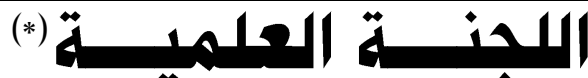

أ. دـ عبدالله محمدل أحمد الجفيمان (جامعة الملك فيصل - السعودية )

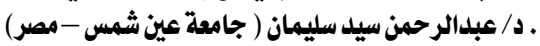

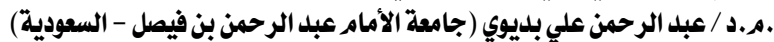

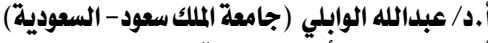

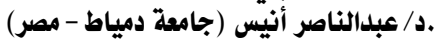

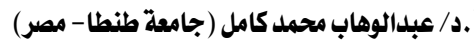

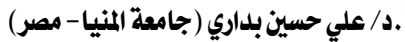

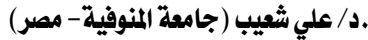

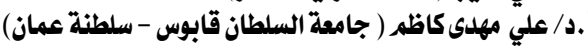

أ. أد/ على محمد هوساوي (جامعة مافير ( الملك سعود - السعودية)

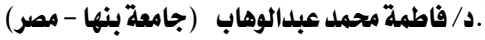

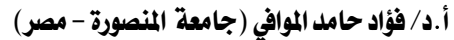

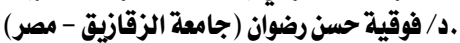

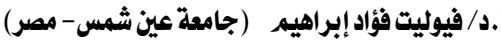

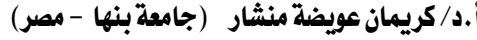

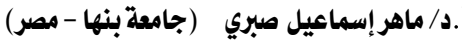

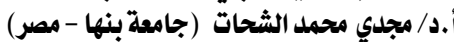

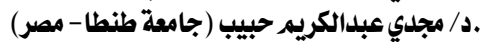

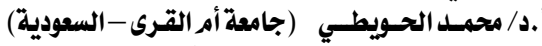

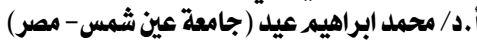

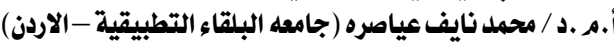

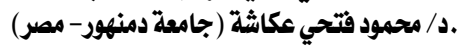

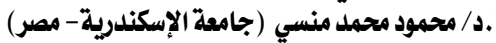

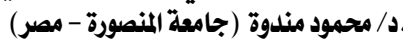

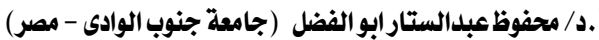

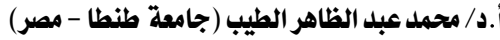

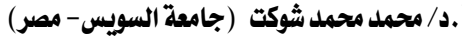

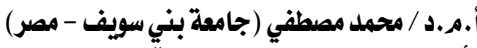

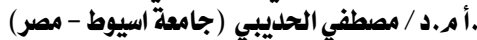

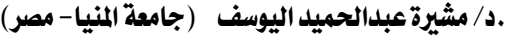

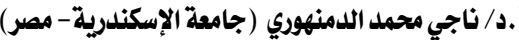

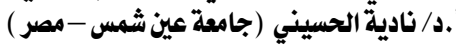

أد/ أناصر سعد العجمي (جامعة الملك سعود - السعودية)

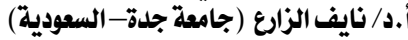

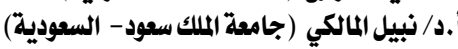

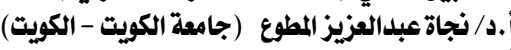

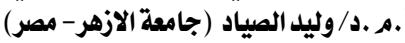

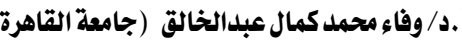

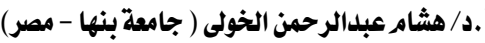

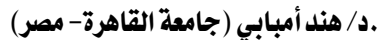

أ.م.د/ ياسر السمـيري (جامعة حائل - السعوديـة)
أ.د/ابتهاج محمود طلبة ( جامعة القاهرة - مصر)

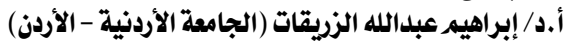

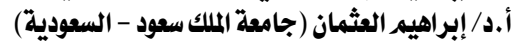
أ. أ.د/ إبراهيه المعيقل (جامعة الملك سعود - السعودية)

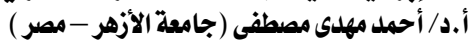

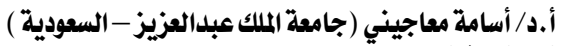

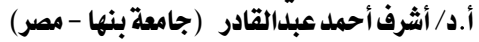
أ.د أشرف عبدالفني شريت( جامعة الإسكندرية - مصر)

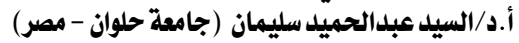

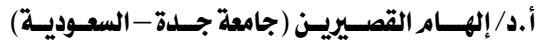

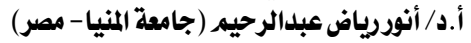

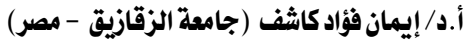

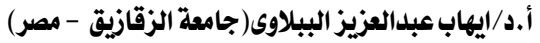
أ. د/ بندر ناصر العتيبى (جامعة الملك سعود- السعودية)

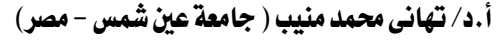

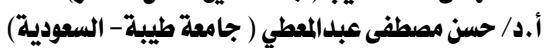

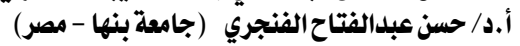

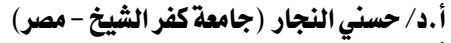
أ.د أد/ حمدي علي الفرماوي (جامعة المنوفية- مصر) أ.د/ خالد رمضآن عبدالفتاح (جامعة الأزهر - مصر)

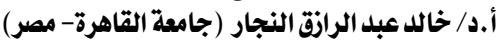

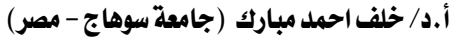
أد/ جمال فايل (جامعة المنصورة - مصر )

أ.د/رشاد عبدالكزيز موسى (جامعة الأزهر - مصر )

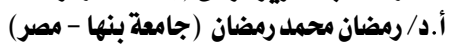
أ. أد/ زيلد محمدل البتال (جامعة الملك سعود - السعودية)

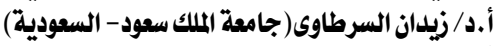

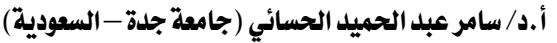

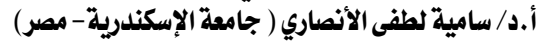

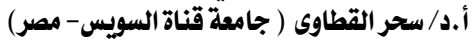
أ.د أد/ سعيد عبل الله ديبيس ( جامعة الملك سعود - السعودية)

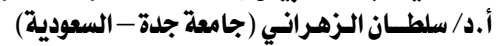

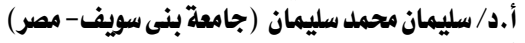

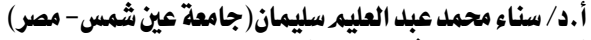
أ.د/ صبحي الحارثي ( جامعة أمر القريع - السعودية)

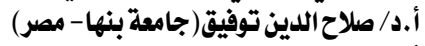

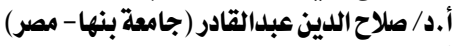
أ. أ.د/ صلاح الدين فرح بخغيت (جالدارين (جامعة الملك سعود - السعودية)

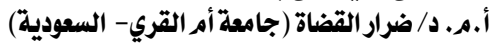

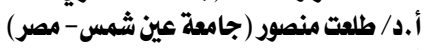
أ.د / عادل محمد العدل (جامعة الزقازيق - مصر)

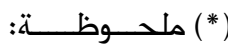

1 - تم ترتيب الأسماء حسب الأبجدية.

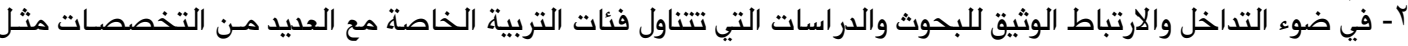

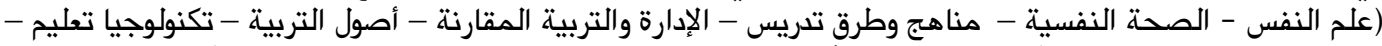

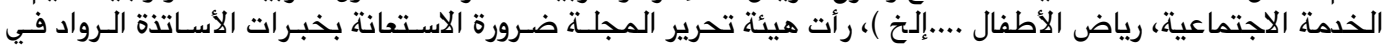

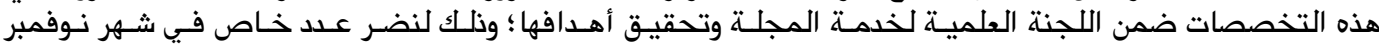

(دراسات وبحوث تربويت ونفسيتة). r- يتم تحديث قائمة السادة المحكمين بشكل مستمرك. 


\section{ق}

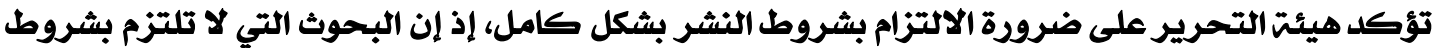
النشر لن ينظر فيها، وتعاد إلى أصحابها مباشرة حتى يتم التقيد بشروط النشرو، ومن هذه الثران الشروط ما يلي:

1 - تدرج الجداول في النص وترقم ترقيمـاً متسلسلاً وتكتب عناوينها فوقها. أما الملاحظات التوضيحية فتكتب تحت الجدول.

v- تلذكر الهوامش وملاحظات وتوضيحات الباحث في آخر الصفحة عند الضرورة. 1- أسلوب التوثيق المعتمد في المجلة هو نظام جمعية علده النفس الأمريكية،

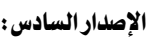

(American Psychological Association- APA-6th ED) 9 - لهيئة التحرير حق الفحص الأولي للبحث، وتقرير أهليته ، أو رفضه للنشر. ـ أ في حالة قبول البحث للنشر تؤول كل حقوق النشر للمجلة، ولا يجوز نشره في أي منفذ نشر آخرورقياً أو الكترونياً، دون أذن كتابي من رئيس هيئة التحرير. 11 - في حالة نشر البحث، يعطي الباحث نسخة من المجلة، وعدد (0) متسلسلات من الدراسة.

rا آ الآراء الواردة في المجلة تعبر عن أراء الباحثين ولا تعبر عن رأي المجلة ، كمـا أن ترتيب البحوث في المجلة لا يخضع لأهمية البحث ولا مكانة الباحث.

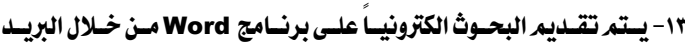
الالكتروني journalofjser@gmail.com مع تعبئة النمساذج الموجهودة

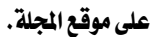

$$
\text { ثانياً : شروط إدارية للنشر }
$$

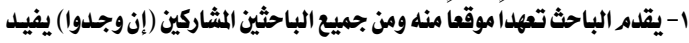

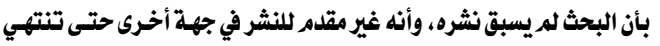

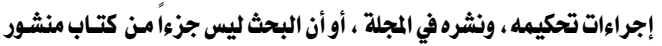

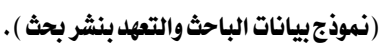

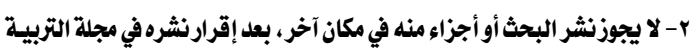
الخاصة والتأهيل، إلا بعد الحصول على إذن كتابي بذلك من رئيس التحان التحرير.

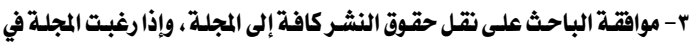
إعادة نشر البحث فإن عليها أن تحصل على مواققة مكتوبة من صاحبه. ولمزيد من المعلومات : يرجى الدخول على الموقع الالكتروني التالي : http://sero.org.eg

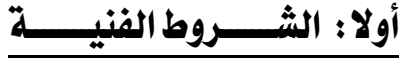 \\ يجب توافر الشروط الفنية التالية عند تسليم البحث

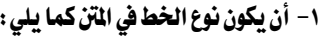

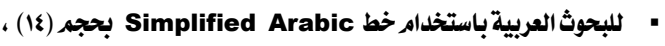

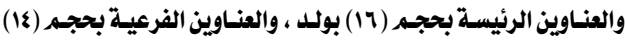

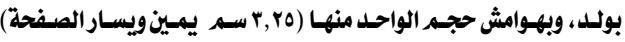

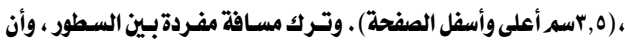

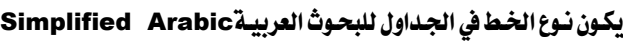

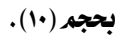

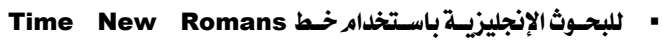

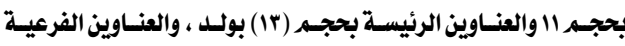

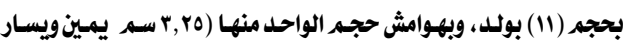

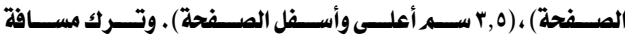

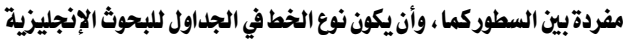
(A) Time New Romans

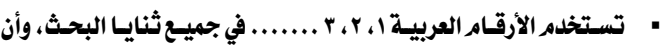
يكوذ ترقيم صفحات البحث في منتصف أسفل الصفحة.

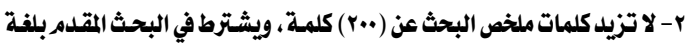
أجنبية أنيلرج فيه ملخص باللفة العربية.

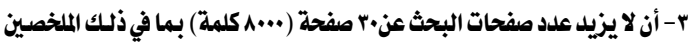

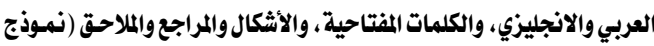
ملخص البحث باللفة العربية واللفة الانجليزية).

ع - أن يكتب عنوان البحث ، واسم الباحث/ الباحثين ، والجامعة/ المؤسسة التي

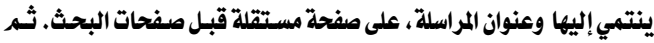

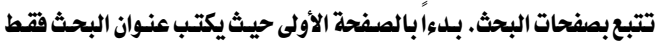

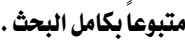
ه - أن يتكون البحث من العناصر التالية :

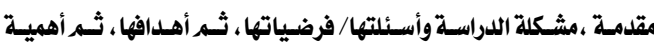

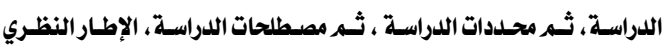

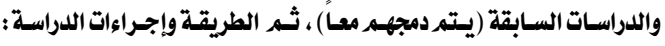

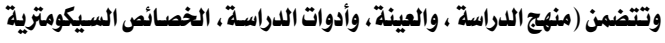
لأدوات الدراسة” الصدق والثبات" وإجراءات الدراسة، والأساليب الإحصائية).

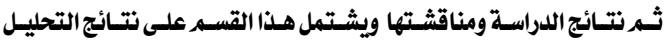

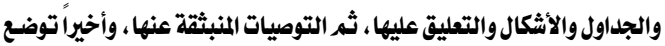

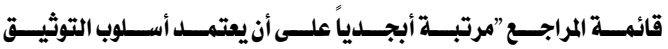

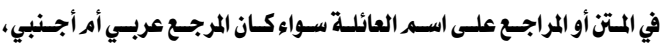

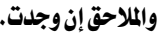




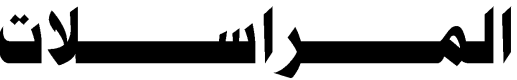

• ترسل البحوث وجميع المراسلات المتعلقة بالمجلة إلى البريد الالكتروني للمجلة: journalofjser@gmail.com

أو إلي مجلس أمناء مؤسسة التربية الخاصة والتأهيل التربوي

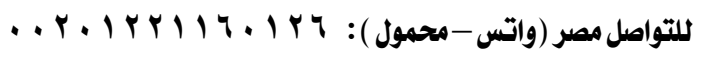

البريد الالكتروني:dralihanafe@hotmail.com

أو الاتصال مباشرة علي سكرتارية مؤسسة التربية الخاصة والتأهيل

$$
(.1 \text {. . } \varepsilon 7 \leqslant 09 \varepsilon v)
$$

• للاستفادة من الاولوية للنشر في المجلة، والحصـول على اعـداد المجلـة ، حضـور ورش

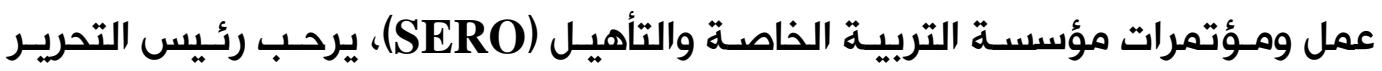
بانضمام البـاحثين في التربيـة الخاصـة لعضـوية المؤسسـة/ المجلـة مـن خـلال زيـارة http://sero.org.eg الموقع الالكتروني للمؤسسة

https://sero.journals.ekb.eg والموقع الالكتروني للمجلة علي بنك المعرفة ، journalofjser@gmail.com وتعبئة نموذج العضوية، وارسال على ايميل المجلـة وحساب المؤسسة ببنك التعميـر والاسـكان فـرع بنهـا (0180000012150)، وتكـاليف النشر في المجلة هي المصـدر الاساسـي لرعايـة الاطفـال ذوى الاعاقـة بالمؤسسـة مـن خلال خدمات الرعاية النهارية بواسطة فريق عمـل متعـدد التخصصـات وجميـع خـدمات التربية الخاصة. 


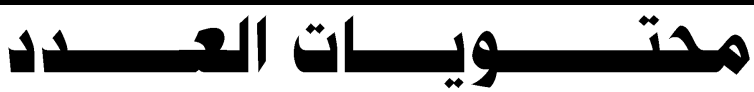

\section{الصفمة}

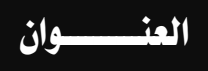

st افتتــاحيــة العــدد

مجلس أمناء مؤسسة التربية الخاصة والتأهيل التربوي (SERO)

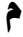
تقديم العــــلـد (رئيس هيئة تحرير المجلة) . أ.ده / عسادل عبدالسه

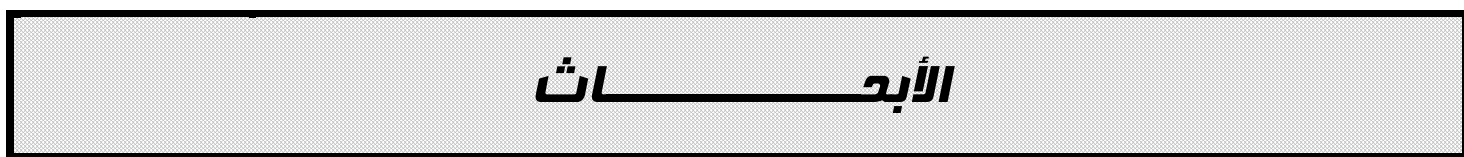

تقيـيم معرفة معلمـات ريـاض الأطفـال بمشكلات الداكرة العاملة لـلدى الأطفـال المعرضـين $r+1$ لخطر صعوبات التعله

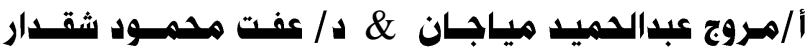

ar - ro

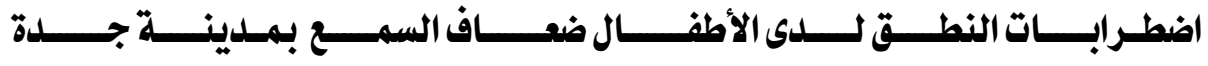

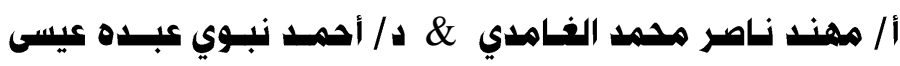

$1.1-70$

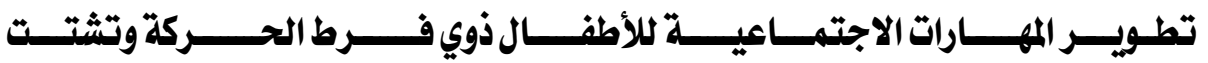
أ / موضي سعود الهويمل \& أ / نوضاء سيف القدطاني \& أ / هناء علي الرويلي العوامل المؤثرة والقوانيز والأسباب الـتي حالت دوذ الـوصـول لنظــاه شـامـل في الـتربيـة أ / أسمساء محمس نـاصر الطيسار

بنـاء وتقـنين بطاريـة مقـاييس لتشخيص الاستعداد النمهائي ( انتبـاه - إدراك - ذاكره) $|0 Y-| r \mid$ للدى تلاميذ المرحلة الابتدائية في مملكة البحرين ... دا ريميسه حسين المطـيري

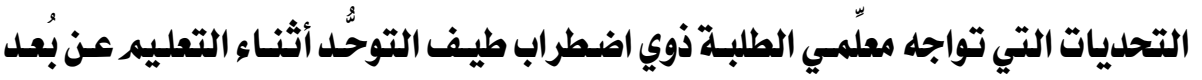
$r \cdot 1-109$ في ظلِ جائحة كورونا أ/دلال كـوض الدـارثي \& د/ ريـم محمـود غـريـب 


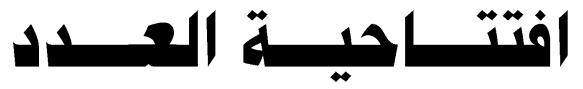

مجلس أمناء مؤسسة التربية الخاصة والتأهيل التربوي

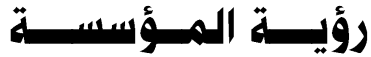 \\ الريادة في النشر العلمي ورعاية وتأهيل وتدريب ذوي الاعاقةوأسرهمروالعاملين في مجال التربية الخاصة على المستويين المحلي والإقليمي}

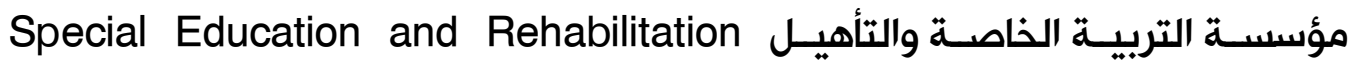

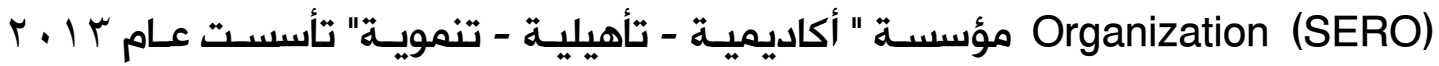

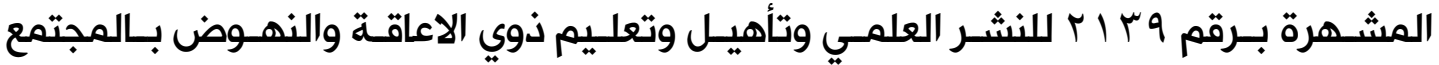

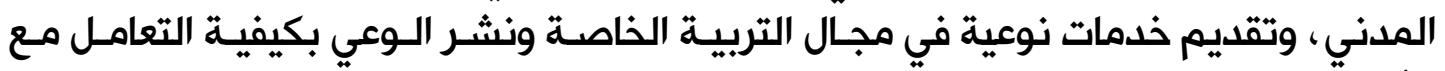

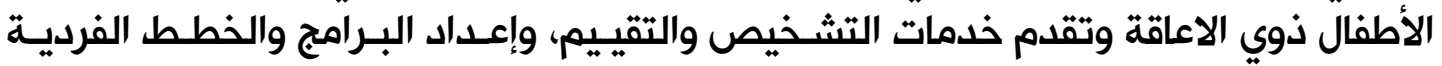

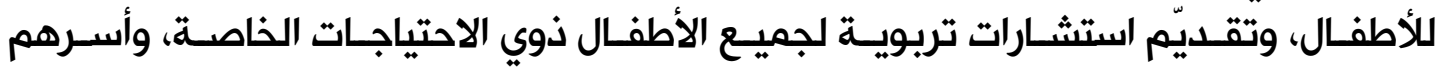
والاختصاصيين في مجال التربية الخاصة والتأهيل. وفي ضوء التطورات التي يشهدها مجال التربية الخاصة، تسعى مؤسلة فئة التربة التربية الخاصة

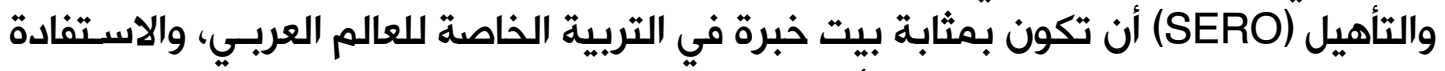

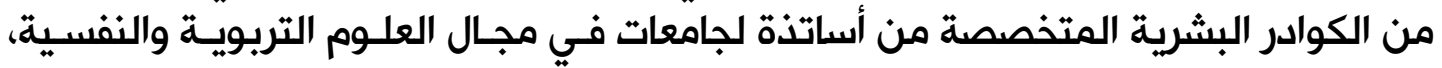

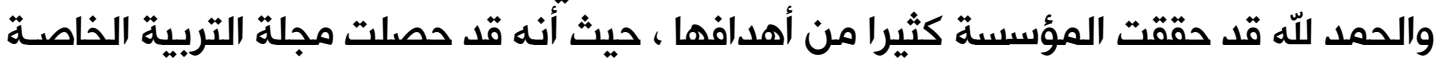

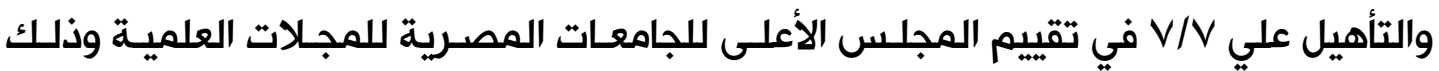

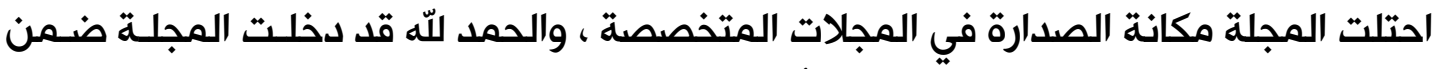

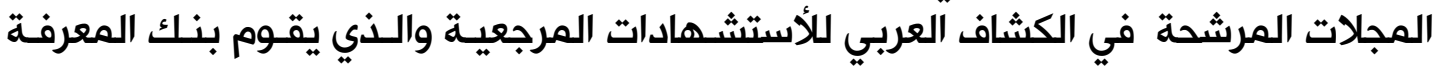

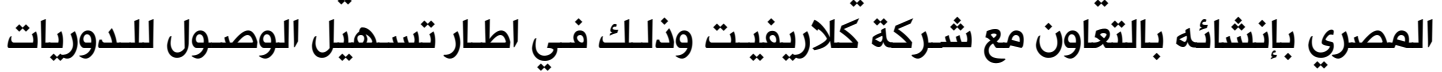
العربية واتاحة بيانات الدوريات العربية للجهات المانحة باندة.

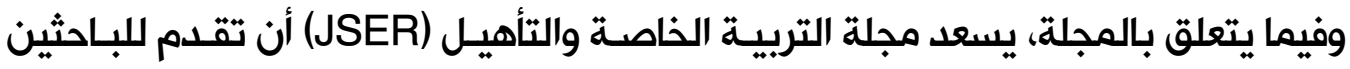

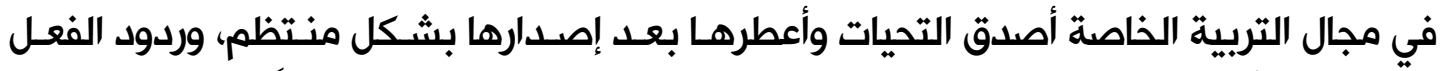

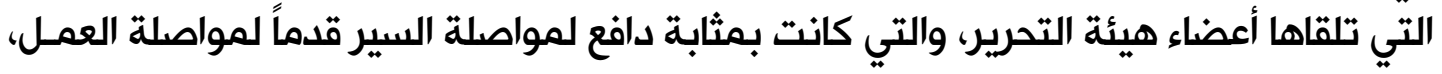

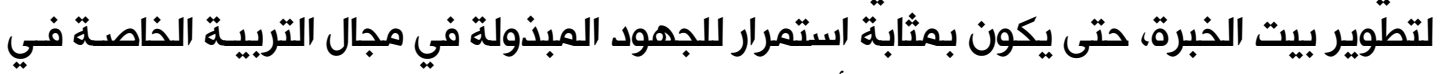

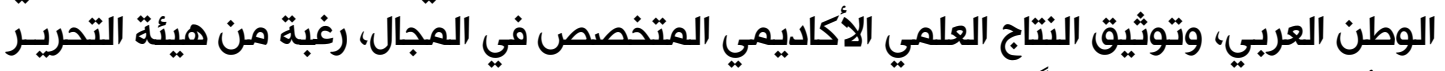

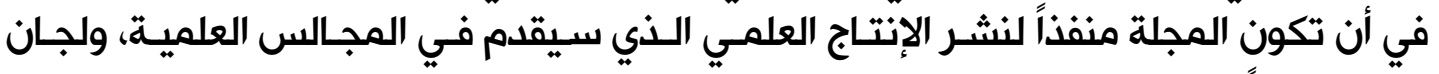

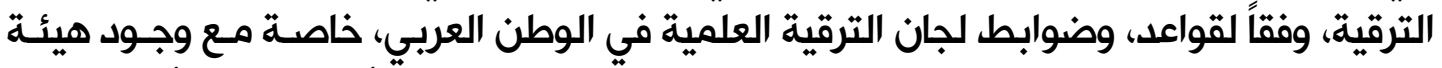

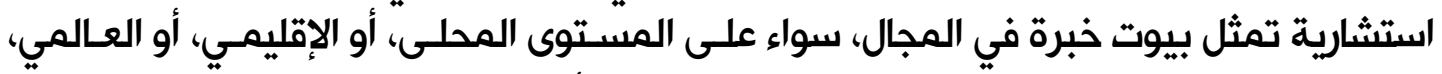

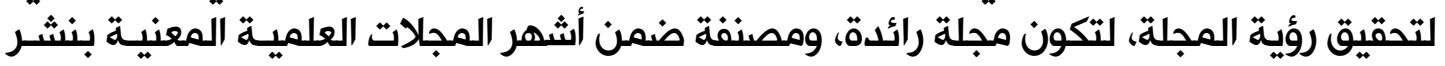
البحوث المحكمة في مجال التربية الخاصة والتأهيل في قواعد البيانات العالمية. 
ويقوم هيئة تحرير المجلة بإعادة العمل على موقع المجلة بما يتوافق مع النشر الاجنبي،

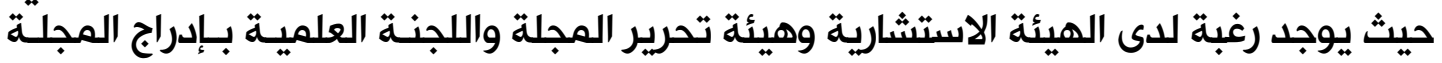

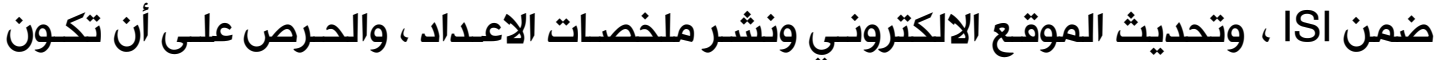

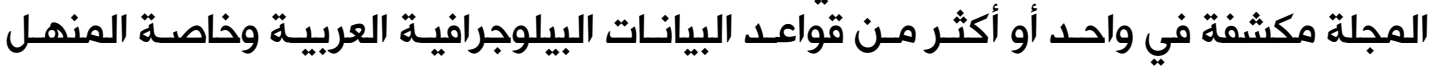

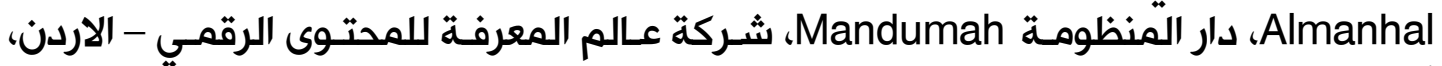

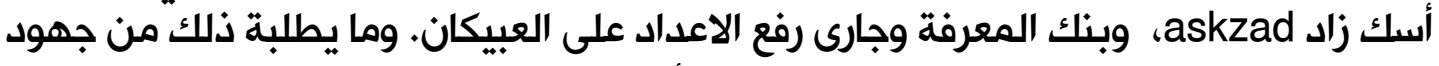

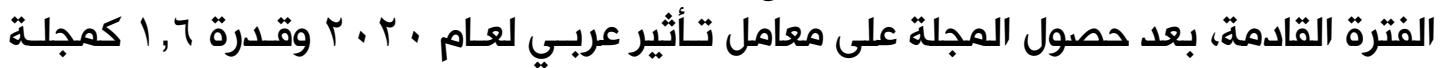

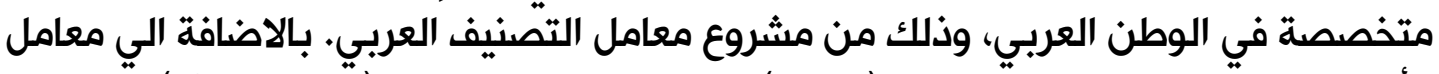

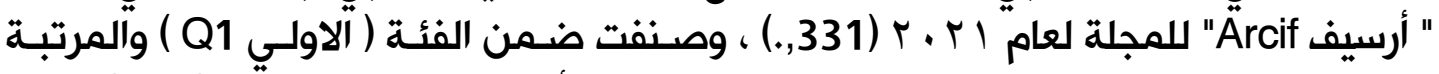

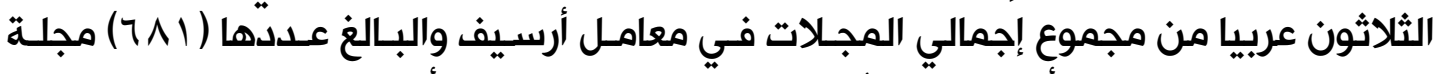

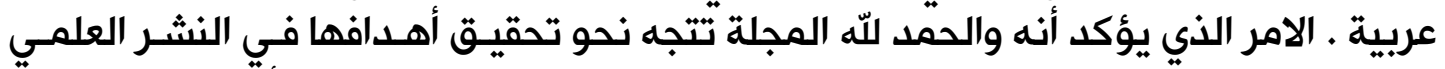

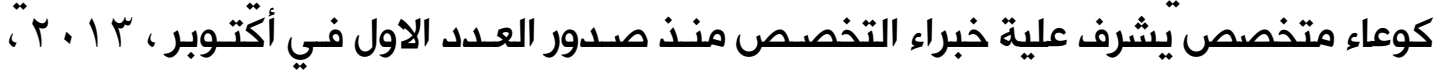

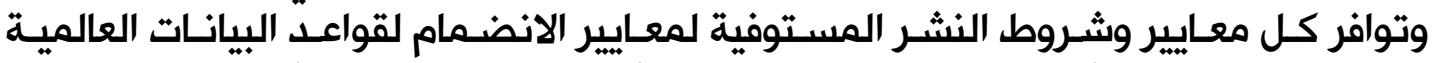
(SCOPUS)

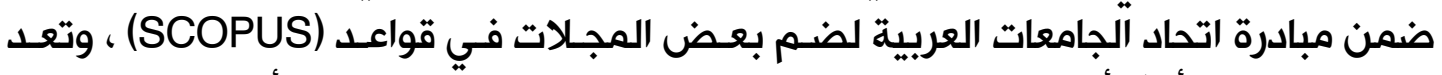

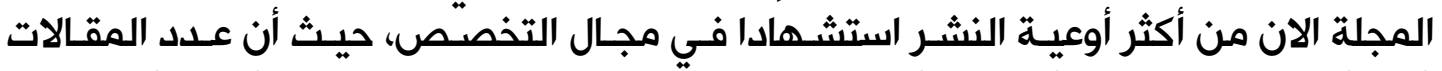

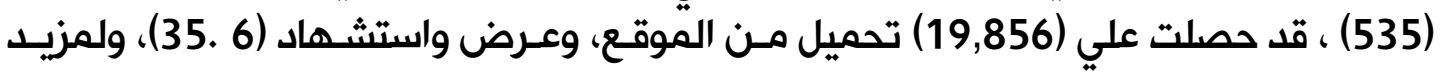

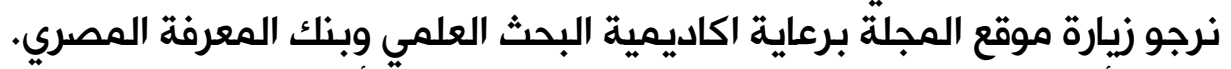

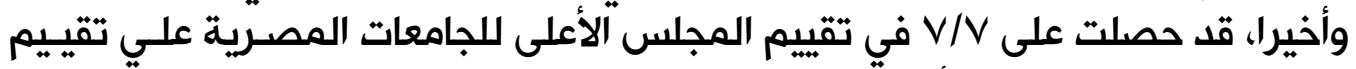

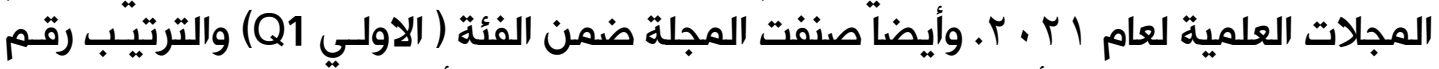

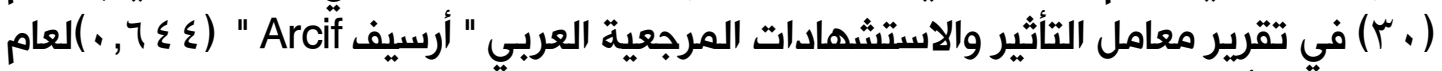

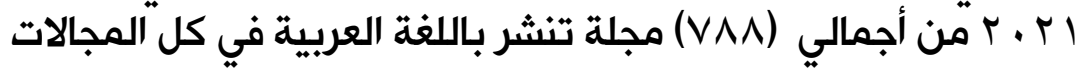

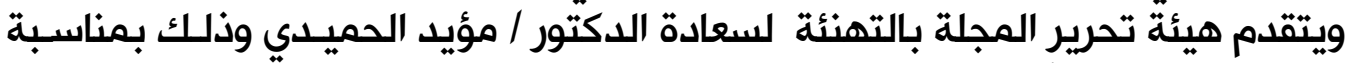

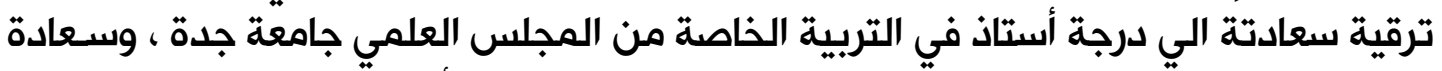

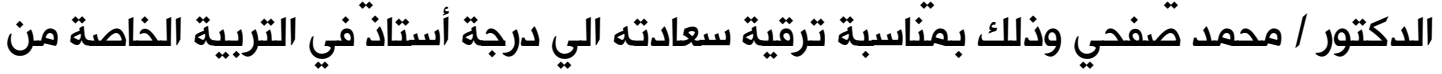

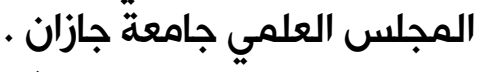

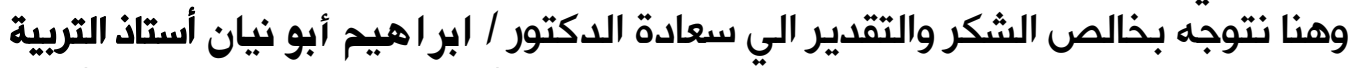

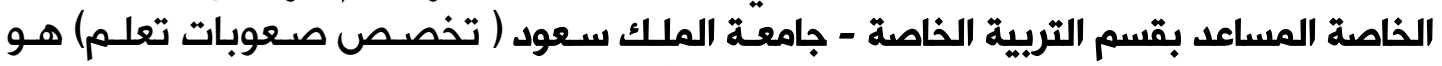

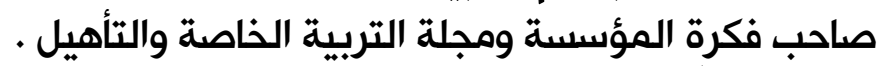

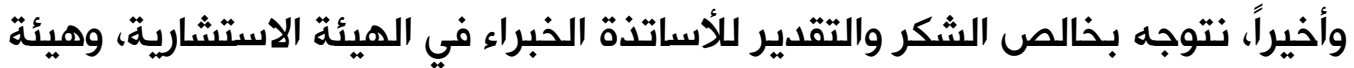

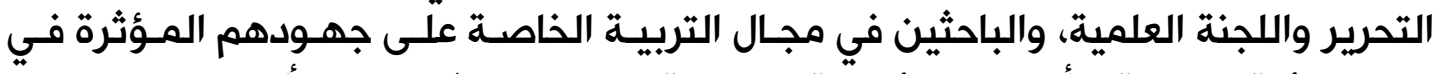

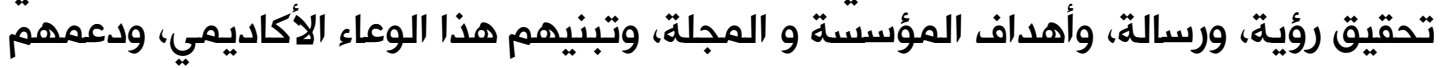
غير المحدود الذي يقدم للارتقاء بالمجلة، لتصبو إلى مجاراة المجلات المولة العالمية. كياتنا وتقربرينا،6، 6

مجلـس أمنـائ مـؤسســة SERO 


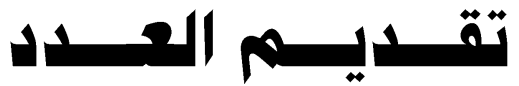

بقلــــم

أ.د/ عادل عبدالله محمد (*)

يشهد العالم حركة سريعة من التقدم والتطور فـي شـتى ميـادين العلـم وخصوصًا مجال التربية الخاصة، ومـا يصـاحبها مـن تطـور متسـارع في حركـة البحث العلمـي لفئـات التربية الخاصة، وما يتعلق بهم من مظاهر سلوكية ومعرفيـة وسـيكولوجية، ومـا يحتـاجون إليه من برامج تنموية وتطويرية وتوجيهية لأدائهم وسلوكهم، ومـا توليـه إيـاهم الجهـات الحكومية والخاصة من سنّ للقوانين والتشـريعات والأنظمـة التـي تيسـر حيـاتهم وتسـهل

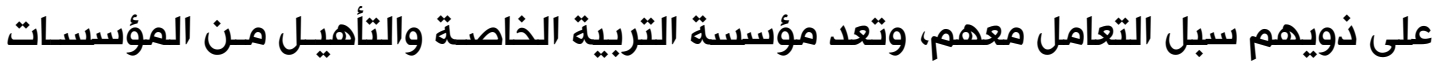

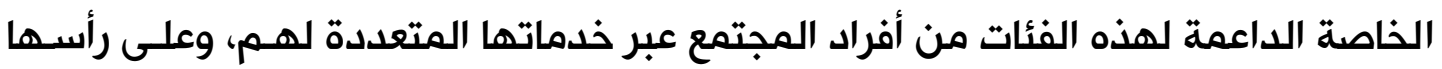
مجلة التربية الخاصة والتأهيل؛ تلك المجلة المتخصصة في هذا المجال على مستوى العـالم

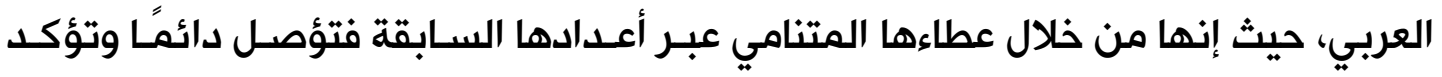

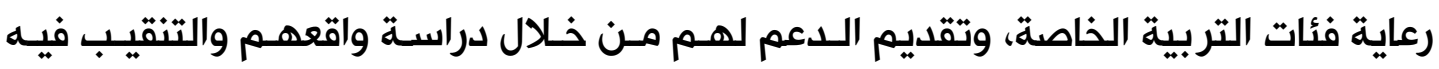
للحصول على أفضل الممارسات المناسبة لهم باختلاف فئاتهم وتصنيفاتهم.

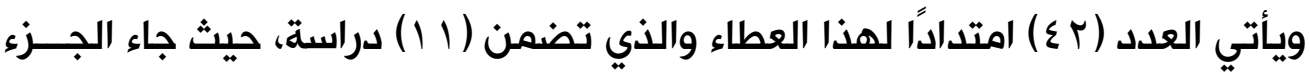

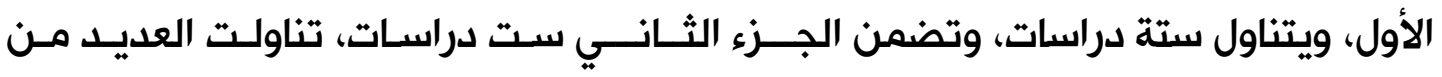

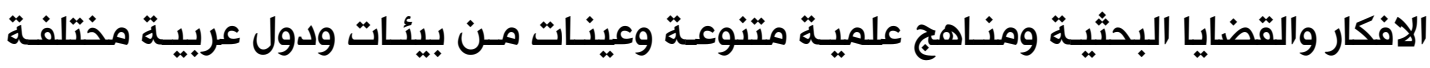
بشكل يؤكد تنوع وتعدد الرؤي البحثية للمجلة.

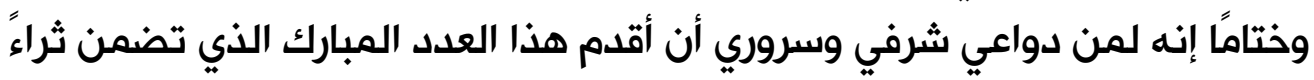

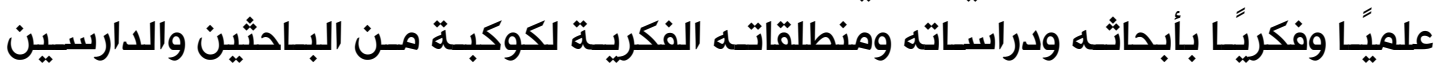

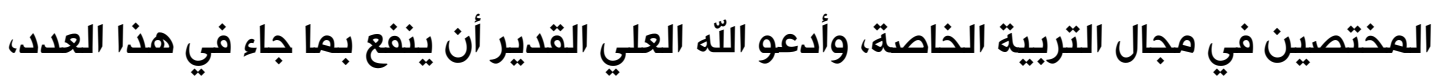

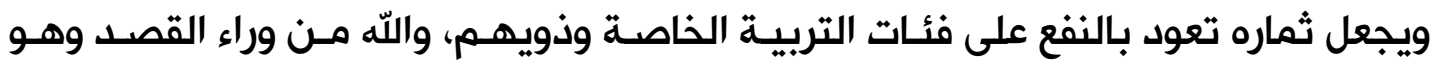
الهادي إلى سواء السبيل،، ولجماءل،

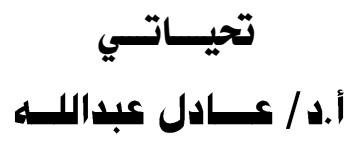

(*) أستاذ التربية الخاصة - عميد ومؤسس كلية علوم الاعاقة جامعـة الزقـازيق سـابقا ، وأحـد خبـراء التربيـة الخاصـة فـي الوطن العربي. 